\title{
Randomised controlled trial of mammographic screening in women from age 40: results of screening in the first 10 years
}

\author{
S Moss", , I Thomas', A Evans' ${ }^{2}$ B Thomas ${ }^{3}$ and L Johns' (writing committee) for the Trial Management \\ Group 4 \\ 'Cancer Screening Evaluation Unit, Institute of Cancer Research, Brookes Lawley Building, 15 Cotswold Road, Sutton, Surrey SM2 5NG, UK; ${ }^{2}$ National \\ Breast Screening Training Centre, City Hospital, Hucknall Road, Nottingham NG5 IPB, UK; ${ }^{3}$ Janvis Breast Screening, Diagnostic and National Training \\ Centre, Stoughton Road, Guildford, Surrey GUI ILJ, UK
}

\begin{abstract}
Debate continues over the effectiveness of screening by mammography in women below age 50. We report here on results of screening in the first 10 years of a randomised trial to study the effect on breast cancer mortality of invitation to annual mammography from age 40 to $4 \mathrm{I}$ compared to first invitation to the 3-yearly UK national programme at age 50-52. The trial is taking place in $23 \mathrm{NHS}$ breast screening centres. Between 1991 and 1997, 160921 women were randomised in the ratio I:2 to intervention and control arms. Screening is by two views at first screen and single view subsequently; data on screening up to and including round five are now complete. Uptake of invitation to screening is between 68 and $70 \%$ at all but the latest screening rounds. Rates of referral for assessment are $4.6 \%$ at first screen and 3.4\% at subsequent screens. Invasive cancer detection rates are $0.09 \%$ at first screen, and similar at rescreens until the sixth and later screens. There is little evidence of regular mammography in the trial control arm. The setting of this trial within the NHS breast screening programme should ensure applicability of results to a national programme.
\end{abstract}

British Journal of Cancer (2005) 92, 949-954. doi:I0.1038/sj.bjc.6602396 www.bjcancer.com

Published online 22 February 2005

(c) 2005 Cancer Research UK

Keywords: breast; screening; mammography; age; trial

The effectiveness of screening for breast cancer by mammography in women below age 50 remains unproven, and is the subject of much debate. While evidence from randomised controlled trials (RCTs) increasingly suggests the existence of some benefit from screening in women below age 50 at trial entry, these trials were not specifically designed to address this question, and the extent to which the observed benefit results from screening in these women after they reach age 50 remains unclear. Analyses of some trials by age at diagnosis suggest a benefit from screening episodes under age 50 , but such analyses reduce the comparability of the intervention and control arms and hence the reliability of the results.

The majority of population-based screening programmes that have been introduced offer screening to women from age 50, although in Sweden some counties invite women from age 40 (Shapiro et al, 1998). In the UK, the effectiveness of screening below age 50 was identified as one of the areas where further research was needed, at the time the national screening programme was introduced (Forrest, 1986). The Age Trial

\footnotetext{
*Correspondence: Dr SM Moss; E-mail: sue.moss@icr.ac.uk

${ }^{4}$ Trial Management Group: Professor H Cuckle (Chair), Professor TJ Anderson, Dr M Cohen, Dr A Evans, Ms J Hayes, DrE Kutt, Dr SM Moss, Dr B Muir, Dr C Record, Dr BA Thomas, Ms I Thomas (Trial Coordinator)

Received 24 September 2004; revised 13 December 2004; accepted I5 December 2004; published online 22 February 2005
}

(International Standard Randomised Controlled Trial Number ISRCTN: 24647151) was designed specifically to study the question of the benefit of starting screening from age 40 . The unique features of this trial are annual mammography (frequently recommended for this age group) and freedom from bias due to screening episodes over age 50.

\section{MATERIALS AND METHODS}

The design of the trial has been described in detail elsewhere (Moss, 1999). The aim was to randomise 195000 women aged $40-$ 41 in a ratio of $1: 2$ to an intervention arm offered annual screening by mammography, and a control arm with no intervention. Women in the intervention arm are invited for screening until the calendar year of their 48th birthday; after age 50 , both they and women in the control arm are eligible for threeyearly invitation as part of the NHS Breast Screening Programme (NHSBSP), and will receive their first invitation between age 50 and 52 years. Screening in the trial is by two-view mammography at the first screen, with single view thereafter unless otherwise indicated. All women, including nonattenders, are reinvited annually unless they ask not to be contacted again. Women who move to areas not covered by the trial are not reinvited for screening as part of the trial, but are able to self-refer to either their previous or their nearest participating screening centre.

The sample size of the trial was calculated to give an $80 \%$ probability of demonstrating as statistically significant a reduction 
of $20 \%$ in breast cancer mortality at 10 years of follow-up at the $5 \%$ significance level, using a one-tailed test, on an 'intention-to-treat' basis. This was based on an estimated cumulative breast cancer mortality of 3.3 per 1000 women in the control group among an initially disease-free population, using the method described by Moss et al (1987).

The trial began in 1991, and includes 23 established NHSBSP centres(Table 1). Randomisation is individual, stratified by GP practice. Women were identified from the (then) Family Health Services Authority (FHSA) computerised register, as is the case for the national screening programme. Women were selected by year of birth to include those who would be 40 or 41 when offered their first invitation or who would become 40 in the calendar year of their first invitation. Prior Notification Lists (PNLs) were generated (before randomisation) and sent to the appropriate GPs for checking and exclusion of women (e.g. known to be dead, wrong age, under care for breast cancer, etc.). Owing to updating of the date of birth information at the screening centres after randomisation (mostly for women in the intervention arm), some women are outside the trial age range, but are included in the analyses.

From 1992, randomisation was carried out using software specifically written for the FHSA computer system. Prior to this, randomisation was carried out using numbers generated from the coordinating centre computer for women in three early centres to join the trial. The date of entry is equal to the date of randomisation, except where randomisation was carried out at the coordinating centre; for one of these centres, date of entry was the date when randomisation lists were returned; for the other two, it was set to a date 8 weeks (the mean interval between date of entry and date of first invitation in centres where randomisation was carried out by the FHSA computer system) before the date of first invitation for women in the intervention arm. For women in the control arm, it was set to the date of entry of those in the intervention arm with the same or nearest date of birth in the same general practice.

Between 1993 and 1995, difficulties were encountered in recruiting new centres, due partly to uncertainties over funding and partly to centres being unable to take on additional workload while maintaining NHSBSP screening. After 1996, no further

Table I Recruitment of centres to the trial

\begin{tabular}{|c|c|c|c|}
\hline Trial centre & $\begin{array}{l}\text { Date centre } \\
\text { joined study }\end{array}$ & $\begin{array}{l}\text { Population } \\
\text { contributed }\end{array}$ & $\begin{array}{l}\text { Cumulative } \\
\text { population }\end{array}$ \\
\hline Guildford & February '9। & 12110 & 12110 \\
\hline Edinburgh & May '91' & 5659 & 17769 \\
\hline Derby & June '92 & 10853 & 28622 \\
\hline Avon & August'92 & 8895 & 37517 \\
\hline Manchester & September '92 & 7181 & 44698 \\
\hline Stoke & September '92 & 8077 & 52775 \\
\hline Epping & October '92 & 6938 & 59713 \\
\hline N. Nottinghamshire & November '92 & 3621 & 63334 \\
\hline Nottingham & November '92 & 8353 & $7 \mid 687$ \\
\hline Worthing & January '93 & 6506 & 78193 \\
\hline Aylesbury & February'93 & 1942 & 80135 \\
\hline Bromley & February '93 & 5834 & 85969 \\
\hline Hull & July '93 & 9793 & 95762 \\
\hline Swindon & November '93 & 4601 & 100363 \\
\hline Bradford & January'94 & 14425 & 114788 \\
\hline Sheffield & July '94 & 6187 & 120975 \\
\hline Warrington & September '94 & 7105 & 128080 \\
\hline Wirral & October '94 & 7047 & 135127 \\
\hline Cumbria & November '94 & 6123 & $14 \mid 250$ \\
\hline North London & January '95 & 4455 & 145705 \\
\hline Peterborough & February '95 & 4393 & 150098 \\
\hline Newcastle & November '95 & 6288 & 156386 \\
\hline Swansea & January '96 & 4535 & $16092 \mid$ \\
\hline
\end{tabular}

centres were recruited; in 1999, the Data Monitoring Committee recommended that recruitment officially cease, and this was subsequently agreed upon by the Trial Steering Committee. A total of 160921 women had been randomised, 53914 to the intervention arm and 107007 to the control arm; the probability of demonstrating a $20 \%$ breast cancer mortality reduction at 10 years of follow-up (under the same assumptions as above) is thus reduced to $73 \%$.

In three centres, Cumbria, Hull and Worthing, screening in the trial ceased prematurely (after four, five and six rounds, respectively) due to inability to manage the additional workload with the available resources. In the primary mortality analysis, women in these centres will be included on an 'intention-to-treat' basis, although analyses taking account of the length of intervention may also be considered.

A woman's first trial invitation within 6 months of entry into the study is defined as round one. After the first invitation, a screening round is defined as the offer of a routine trial screen in a 10-14 month period following the previous screen (or invitation to screen). A woman may accrue more than eight screening rounds during the trial, depending on her age in the calendar year of her first invitation. Uptake and outcome of screening are presented by screening rounds, with results combined for later screening rounds as yet incomplete.

An interval cancer is defined as one diagnosed following a negative screen (including return to routine recall following assessment) and occurring before the next offered appointment. Cancers in lapsed attenders are those cancers occurring in women whose last attended screen was negative and who were diagnosed after declining subsequent invitations to attend. Cancers in women who have moved away from their original centre and hence no longer invited are included as 'lost to screening'.

Recruitment of centres to the trial took place between 1991 and 1996 (Table 1), with randomisation ending in 1997. Results in the present paper include data up to 31st March 2002, with a mean of 8.0 years follow-up from the date of entry. Owing to incomplete ascertainment of breast cancers in the most recent years, incidence rates and the analysis of sensitivity of screening are based on data up to 31st December 1999.

Woman-years for analysis of all-cause mortality are calculated from each woman's date of entry to date of death or 31st March 2002, whichever is earlier. Those for analyses of incidence are calculated from the date of entry to the date of death or $31 \mathrm{st}$ December 1999, whichever is earlier, and are also censored at the date of diagnosis of breast cancer.

The sensitivity of screening at different screening rounds has been estimated by the 'proportional incidence' method (Day, 1985), using age-specific incidence rates in the control arm to calculate the expected numbers of cancers in the absence of screening. Owing to the fact that the observed incidence in the never-attenders is lower than that in the control arm, the expected incidence $i_{\mathrm{a}}$ in the attenders has been calculated for each round (assuming everyone is age 40 at first screen, 41 at second screen, etc.) as

$$
i_{\mathrm{a}}=\left(i_{\mathrm{c}}-(1-p) i_{\mathrm{na}}\right) / p
$$

where $p$ is the the proportion of ever-attenders, $i_{c}$ is the agespecific incidence rate in the control arm (based on a 3-year moving average) and $i_{\text {na }}$ is the incidence rate in the nonattenders.

Owing to fluctuation due to small numbers, $i_{\text {na }}$ is estimated as $i_{\mathrm{c}} \times I_{\text {na }} / I_{\mathrm{c}}$, where $I_{\text {na }}$ and $I_{\mathrm{c}}$ are the overall incidence rates in the nonattenders and control arm, respectively.

The primary end point of the trial is a comparison of mortality from breast cancer in the two arms of the trial, in women free from breast cancer at date of entry. All women in the trial are flagged at the National Health Service Central Register (NHSCR), which provides information on deaths from all causes and on cancer 
incidence. However, a detailed pathology review is also being undertaken (Anderson et al, 2002), to enable an earlier analysis based on surrogate outcome measures to be performed (Moss et al, 2005).

A radiology review is also being undertaken of all screendetected, interval and lapsed-attender cancers notified in the trial, in order to identify and highlight the radiological features most frequently missed or misinterpreted when screen reading the mammographic films of younger women, and to identify which features are most helpful to observe when reading mammograms of younger women. The results of this review will be submitted for publication at a later date. During the course of the trial, radiation doses were collected and reviewed; the findings of this work have been published elsewhere (Young, 2002).

'Contamination' with private screening in the trial's control population was assessed by postal questionnaires sent to a total of 3755 women in five participating centres, asking about past mammography for both symptomatic and screening purposes. Women were aged $42-49$ years at the time of the survey.

\section{RESULTS}

Figure 1 and Table 2 show the number of women randomised by trial arm and by individual year of age. A total of 160921 women were randomised after checking of lists by GP's; more than $99.9 \%$ of women randomised have been successfully traced and flagged at NHSCR. A total of 60 women were excluded from analyses for reasons given in the flowchart (Figure 1).

Table 3 shows the uptake of screening at successive rounds, and also demonstrates the loss of women to screening, with $84.3 \%$ of women randomised to the intervention arm invited at round five.
A total of 1215 women were first invited more than 6 months after their date of entry, and therefore were not invited in round one according to our definition. A further 82 women were never invited due to updates in their Health Authority information, which made them ineligible for invitation (e.g. they were under care or had moved away).

For routine trial screens, $94 \%$ of appointments were offered between 10 and 14 months after the previous screen, and $56 \%$ after 12 months ( \pm 2 weeks). In all, $93 \%$ of screens attended took place at $10-14$ month intervals.

Data on screening up to and including round five are now complete, but women with the earliest dates of entry will have six or more rounds. Women in the intervention arm have received a mean of 6.6 routine invitations compared with a potential of 7.5 if there had been no loss to follow-up. Uptake of invitations is

Table 2 Number of women randomised

\begin{tabular}{|c|c|c|c|c|}
\hline \multirow[b]{2}{*}{ Age at entry } & \multicolumn{2}{|c|}{ Intervention arm } & \multicolumn{2}{|c|}{ Control arm } \\
\hline & $n$ & $\%$ & $n$ & $\%$ \\
\hline$<38$ & 21 & $<0.1$ & 8 & $<0.1$ \\
\hline 38 & 158 & 0.3 & 285 & 0.3 \\
\hline 39 & 16724 & 31.0 & 32841 & 30.7 \\
\hline 40 & 26387 & 49.0 & $52|4|$ & 48.7 \\
\hline 41 & 10419 & 19.3 & 21597 & 20.2 \\
\hline$>41$ & 181 & 0.3 & 99 & 0.1 \\
\hline Total & 53890 & & |0697| & \\
\hline Mean age at entry & \multicolumn{2}{|c|}{40.38} & \multicolumn{2}{|c|}{40.39} \\
\hline
\end{tabular}

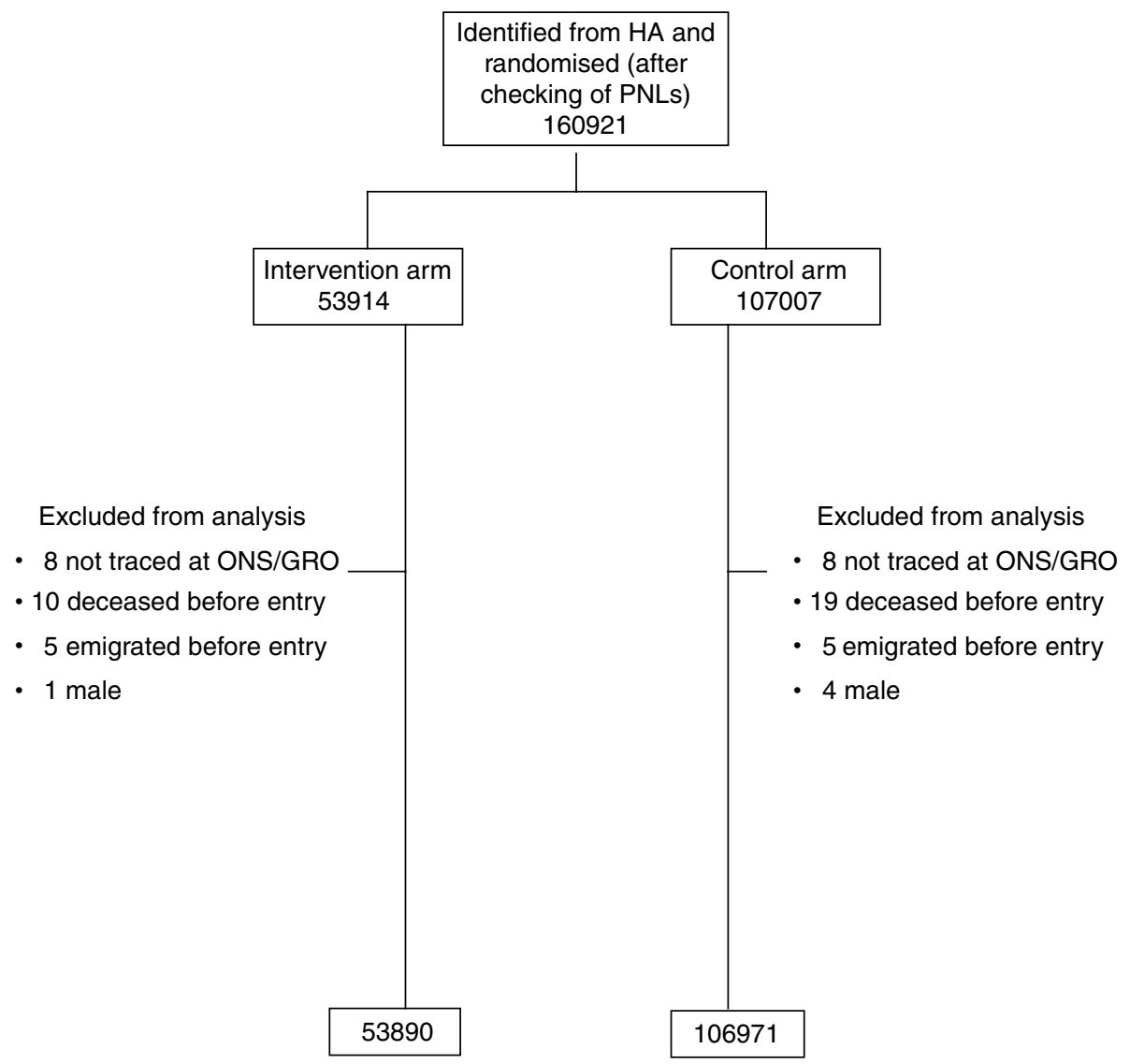

Figure I Flow diagram of the progress through the phases of the trial. 
between 68 and $70 \%$ at each round up to round eight, and increases with number of previous attendances; uptake is over $95 \%$ in women who have attended at least five previous screens.

In all, $81 \%$ of women in the intervention arm have attended at least one invitation for routine screening, and of these, $50 \%(41 \%$ of the intervention arm) have attended all their invitations to routine screening within the trial.

\section{Screening performance}

Table 4 shows the numbers and rates of referrals for assessment, biopsies and in situ and invasive cancers detected, by screening round. Mean age will increase with successive rounds, and the rates analysed by age at screening are very similar to those by screening round. Overall rates of referral for assessment are $4.6 \%$ at first screen (first invitation) and $3.4 \%$ at subsequent screens. Invasive cancer detection rates are $0.09 \%$ at first screen, and similar at rescreens until the sixth and later screens. Detection rates of in situ cancer (including microinvasive) are $0.02 \%$ at first invitation, and increase slightly in the latest rounds. Rates of referral, biopsy and cancer detection are raised in first screens of previous nonresponders.

Table 3 Women invited and uptake of screening (data up to 3I March 2002)

\begin{tabular}{|c|c|c|c|c|}
\hline \multirow{2}{*}{$\begin{array}{l}\text { Screening } \\
\text { round }\end{array}$} & \multirow{2}{*}{$\begin{array}{l}\text { Women } \\
\text { invited }\end{array}$} & \multicolumn{2}{|c|}{$\begin{array}{l}\text { Women } \\
\text { screened }\end{array}$} & \multirow[b]{2}{*}{$\%$ Population screened $^{a}$} \\
\hline & & $\boldsymbol{n}$ & $\%$ & \\
\hline I & 52593 & 35846 & 68 & 67 \\
\hline 2 & 48942 & 33784 & 69 & 63 \\
\hline 3 & 46985 & 31961 & 68 & 59 \\
\hline 4 & 45640 & $3|3| 1$ & 69 & 58 \\
\hline 5 & 45451 & 31334 & 69 & 58 \\
\hline 6 & 43030 & 29693 & 69 & \\
\hline 7 & 37062 & 26061 & 70 & Incomplete screening rounds \\
\hline 8 & 26832 & 18805 & 70 & \\
\hline$\geqslant 9$ & 8923 & 5917 & 66 & \\
\hline
\end{tabular}

${ }^{a}$ Number of intervention arm women screened (by round) expressed as a proportion of the number potentially available for invitation on the basis of the amount of time elapsed since each woman entered the trial.
Table 5 gives the numbers of breast cancers in the control arm and in the intervention arm by method of detection. The incidence rate in women in the intervention arm never attending screening is 1.03 per 1000 women-years, compared with 1.32 per 1000 womenyears in the control arm. The incidence rate in the intervention arm is 1.54 per 1000 women-years. A total of 99 invasive interval cancers (plus five in situ) have been detected in the 12 months following a negative screen (including return to routine recall following assessment). A further 21 cancers (invasive and in situ) have been detected after 12 months but before the woman had received her next invitation. In all, 44 cancers occurred in women who have failed to attend for later screens, and 14 in the 'lost to screening' group.

Table 6 shows the numbers of observed and expected invasive interval cancers; the sensitivity of the first screen is $73.6 \%$, and of subsequent screens is $54.1 \%$. For subsequent screens, sensitivity increases from $46.8 \%$ at screens two and three to $64.5 \%$ at screen six or later.

\section{All-cause mortality}

Table 7 shows the mortality from all causes excluding breast cancer, which is similar in the two arms of the trial (control: 1.29; intervention 1.34 per 1000 women years).

Table 5 Breast cancers by method of detection (data up to 31 December 1999)

\begin{tabular}{lcc}
\hline & Intervention arm & Control arm \\
\hline Between randomisation and invitation & 9 & \\
Never-attenders & 61 & \\
Screen detected: total & 229 & \\
Interval cancers & & \\
$\quad$ Before next invitation & 125 & \\
Lapsed attenders & 44 & \\
'Lost to screening' & 14 & 821 \\
Total & 482 & \\
\hline
\end{tabular}

In situ and microinvasive cases included.

Table 4 Outcome of screening (data up to 3I March 2002)

\begin{tabular}{|c|c|c|c|c|c|c|c|c|c|c|c|c|c|}
\hline & $\begin{array}{c}\text { No. } \\
\text { screened }\end{array}$ & Referred & $\begin{array}{c}\% \text { of } \\
\text { screened }\end{array}$ & Biopsied & $\begin{array}{c}\% \text { of } \\
\text { screened }\end{array}$ & $\begin{array}{l}\text { In situ } \\
\text { cancer } \\
\text { detected }\end{array}$ & $\begin{array}{c}\% \text { of } \\
\text { screened }\end{array}$ & $\begin{array}{l}\text { Invasive } \\
\text { cancer } \\
\text { detected }\end{array}$ & $\begin{array}{c}\% \text { of } \\
\text { screened }\end{array}$ & $\begin{array}{c}\text { Total } \\
\text { cancer } \\
\text { detected }\end{array}$ & $\begin{array}{c}\% \text { of } \\
\text { screened }\end{array}$ & $\begin{array}{c}\text { PPV of } \\
\text { assessment } \\
\%\end{array}$ & $\begin{array}{c}\text { PPV of } \\
\text { biopsy } \\
\%\end{array}$ \\
\hline First invitation & 35846 & 1655 & 4.6 & 93 & 0.26 & $6^{a}$ & 0.02 & 31 & 0.09 & 37 & 0.10 & 2 & 40 \\
\hline $\begin{array}{l}\text { First screening } \\
\text { round in previous } \\
\text { nonresponders }\end{array}$ & 7679 & 511 & 6.7 & 48 & 0.63 & 3 & 0.04 & 14 & 0.18 & 17 & 0.22 & 3 & 35 \\
\hline $\begin{array}{l}\text { Second routine } \\
\text { screening round }\end{array}$ & 39912 & 1324 & 3.3 & 70 & 0.18 & 8 & 0.02 & 33 & 0.08 & 41 & 0.10 & 3 & 59 \\
\hline $\begin{array}{l}\text { Third routine } \\
\text { screening round }\end{array}$ & 37128 & 1323 & 3.6 & 77 & 0.21 & 8 & 0.02 & 34 & 0.09 & 42 & 0.11 & 3 & 55 \\
\hline $\begin{array}{l}\text { Fourth routine } \\
\text { screening round }\end{array}$ & 34082 & $116 \mid$ & 3.4 & 75 & 0.22 & $9^{a}$ & 0.03 & 28 & 0.08 & 37 & 0.11 & 3 & 49 \\
\hline $\begin{array}{l}\text { Fifth routine } \\
\text { screening round }\end{array}$ & 29818 & 989 & 3.3 & 61 & 0.20 & $12^{b}$ & 0.04 & 23 & 0.08 & $37^{c}$ & 0.12 & 4 & 61 \\
\hline $\begin{array}{l}\text { Subsequent } \\
\text { routine screening } \\
\text { rounds }\end{array}$ & 60206 & 2072 & 3.4 & 166 & 0.28 & $28^{d}$ & 0.05 & 69 & 0.11 & $98^{e}$ & 0.16 & 5 & 59 \\
\hline
\end{tabular}

PPV = positive predictive value. ${ }^{a}$ This value includes one microinvasive case. ${ }^{\mathrm{b}}$ This value includes four microinvasive cases. ${ }^{\mathrm{c}}$ This value includes two cases where invasive status is not known. ${ }^{\mathrm{d}}$ This value includes two microinvasive cases. ${ }^{\mathrm{e}}$ This value includes one case where invasive status is not known. 


\section{Screening in the control arm}

Of the 3755 women sent questionnaires, 2115 (56.3\%) responded and $2041(54.4 \%)$ were suitable for analysis. Of these, $18 \%$ reported ever having had a mammogram for symptomatic reasons, and $8.4 \%$ reported having had a screening mammogram, $3.9 \%$ within the past 3 years.

\section{DISCUSSION}

Despite lower mortality from breast cancer at younger ages, the issue of the effectiveness of screening below age 50 is an important public health question in the UK, due to both demands from the women concerned and the possible implications for the NHS. Although cancer incidence in women in their 40 s is approximately half that of women in their 50s, the proportion of all female deaths due to breast cancer is higher in women in their 40s. A third of lifeyears lost due to breast cancer occurs in women diagnosed with breast cancer in their $40 \mathrm{~s}$.

The benefit of mammographic screening was established principally from mortality data on women screened at age 50 or older, and while comparable data in younger women are available from some of the RCTs, none included sufficient numbers to reliably estimate the mortality effect. The most recent overview of the Swedish trials found a relative risk of 0.80 (95\% CI $0.63,1.01)$ in women aged 40-49 at entry at a median of 15.8 years of followup (Nystrom et al, 2002). This analysis excluded the Kopparberg arm of the Two County Study. An earlier overview had found a nonsignificant $13 \%$ reduction at an average of 9 years of follow-up, the difference emerging after 8 years. A meta-analysis of all RCTs including the Canadian NBSS1 trial found a reduction of $18 \%$ in this age group (Hendrick et al, 1997). The Canadian NBSS1 trial,

Table 6 Interval cancers and estimate of sensitivity (data up to 31 December 1999)

\begin{tabular}{lccc}
\hline & $\begin{array}{c}\text { Interval cancers } \\
\text { within I2 } \\
\text { months (O) }\end{array}$ & $\begin{array}{c}\text { Expected } \\
\text { cancers (E) }\end{array}$ & Sensitivity $^{\mathbf{a}}$ (\%) \\
\hline Ist screen & 13 & 49.4 & 73.6 \\
2nd and 3rd screen & 47 & 88.4 & 46.8 \\
4th and 5th screen & 28 & 68.1 & 58.9 \\
Later screens & 11 & 31.0 & 64.5 \\
\hline
\end{tabular}

In situ and microinvasive cases excluded. ${ }^{a}(I-O / E) \times 100 \%$. which was designed to compare the effect of screening by mammography and physical examination with an initial physical examination only in women aged 40-49 at entry, has suffered from low statistical power, and has also been criticised for the use of a volunteer population and doubts about the quality of mammography. After 11-16 years of follow-up, this trial has shown no difference in breast cancer mortality between the two arms (Miller et al, 2002).

Cancer detection rates in the current trial do not increase greatly with age until the later screening rounds at ages 46 or more. Rates of recall for assessment are lower, particularly at the first screen, than for women aged 50-64 in the national programme, but the lower cancer detection rate means that the positive predictive value of recall is lower.

In the early years of the trial, concerns were raised about the uptake of screening that could be achieved in this age group, and about the extent of screening in the control arm, which would dilute any observed effect. In the event, uptake of invitation has remained satisfactory at around $70 \%$, although it appears to fall slightly in the final round(s). The 'loss to screening' due to women moving is similar to that which has occurred in other trials, such as the UK Trial of Early Detection of Breast Cancer (Moss et al, 1999). Our estimates of the extent of screening in the control arm show little evidence of regular mammography.

The current trial has used annual invitation for screening due to concerns about lower sensitivity of mammography and possible faster mean growth rate of tumours in this age group.

There are limited data available from other studies on cancer detection rates in this age group, particularly at the lower end, and most rates are for women aged 40-49. In the Gothenburg trial, which included five rounds at intervals of 18 months, detection rates in women aged $40-44$ at entry were $0.07 \%$ at first screen, and 0.18 at subsequent screens.

The trial is set completely within the NHSBSP framework; while this has caused some logistical problems where programmes have had to balance the trial requirements with those of the national programme, it should ensure the applicability of the results to the UK programme.

Uptake in this trial is likely to be lower than would be seen if the national programme were extended to this age group. There has been no health promotion associated with the trial, in order to avoid increasing demand for screening in the control arm. In addition, women who have moved to centres not participating in the trial will not have continued to be routinely invited for screening.

Table 7 All-cause mortality excluding breast cancer, by year in trial (data up to 31 March 2002)

\begin{tabular}{|c|c|c|c|c|c|c|c|c|c|c|c|c|}
\hline \multirow[b]{2}{*}{$\begin{array}{l}\text { Year in } \\
\text { trial }\end{array}$} & \multicolumn{4}{|c|}{ Control arm } & \multicolumn{4}{|c|}{ Intervention arm } & \multicolumn{4}{|c|}{ Total } \\
\hline & $\begin{array}{l}\text { No. of } \\
\text { women }\end{array}$ & $\begin{array}{c}\text { Woman- } \\
\text { years }\end{array}$ & Deaths & $\begin{array}{c}\text { Rate per } \\
1000 \mathrm{w} \\
\text { years }\end{array}$ & $\begin{array}{l}\text { No. of } \\
\text { women }\end{array}$ & $\begin{array}{c}\text { Woman- } \\
\text { years }\end{array}$ & Deaths & $\begin{array}{l}\text { Rate per } \\
1000 \mathrm{w} \\
\text { years }\end{array}$ & $\begin{array}{l}\text { No. of } \\
\text { women }\end{array}$ & $\begin{array}{l}\text { Woman- } \\
\text { years }\end{array}$ & Deaths & $\begin{array}{c}\text { Rate per } \\
1000 \mathrm{w} \\
\text { years }\end{array}$ \\
\hline 1 & |0697| & 106908 & 86 & 0.80 & 53890 & 53862 & 42 & 0.78 & | $6086 \mid$ & 160770 & 128 & 0.80 \\
\hline 2 & |06 87| & 106824 & 107 & 1.00 & 53847 & 53822 & 61 & 1.13 & 160718 & 160646 & 168 & 1.05 \\
\hline 3 & 106746 & 106669 & 121 & 1.13 & 53777 & 53739 & 61 & 1.14 & 160523 & 160408 & 182 & 1.13 \\
\hline 4 & 106609 & 106538 & 137 & 1.29 & 53711 & 53669 & 82 & 1.53 & 160320 & | 60207 & 219 & 1.37 \\
\hline 5 & 106449 & 106346 & 138 & 1.30 & 53623 & 53574 & 73 & 1.36 & 160072 & 159920 & 211 & 1.32 \\
\hline 6 & 106276 & 104648 & 152 & 1.45 & 53533 & 52698 & 79 & 1.50 & | 59809 & 157346 & 231 & 1.47 \\
\hline 7 & 100386 & 92599 & 137 & 1.48 & 50539 & 46660 & 68 & 1.46 & 150925 & 139259 & 205 & 1.47 \\
\hline 8 & 84076 & 69840 & 116 & 1.66 & 42398 & 35188 & 62 & 1.76 & 126474 & 105028 & 178 & 1.69 \\
\hline 9 & 54314 & 42284 & 77 & 1.82 & 27326 & 21252 & 36 & 1.69 & 81640 & 63536 & 113 & 1.78 \\
\hline 10 & 30375 & 16539 & 42 & 2.54 & 15278 & 8343 & 15 & 1.80 & 45653 & 24882 & 57 & 2.29 \\
\hline II & 7470 & 4245 & 4 & 0.94 & 3739 & 2011 & 5 & 2.49 & | | 209 & 6256 & 9 & 1.44 \\
\hline Total & & 863440 & 1117 & 1.29 & & 434818 & 584 & 1.34 & & | 298258 & $170 \mid$ & 1.31 \\
\hline
\end{tabular}


While fieldwork is continuing, there is likely to remain an excess of breast cancers in the intervention arm due to advancement of diagnosis. Screening data collection will continue until all women have been invited for screening as part of the national programme, by which time incidence rates would be expected to be equal in the two arms; this will take until 2009. The trial was designed to compare mortality from breast cancer at 10 years of follow-up. This length of follow-up has now been achieved and a mortality analysis will be conducted once it is decided that data ascertainment is complete. Estimates of mortality reduction based on pathology variables have been made (Moss et al, 2005), but conclusions as to the effectiveness and cost-effectiveness of screening in this age group must await definitive results on mortality.

\section{ACKNOWLEDGEMENTS}

The trial is supported by grants from the Medical Research Council and Cancer Research UK, and has also received funding from the Department of Health. Additional funding has been received from the US National Cancer Research Institute. We would like to acknowledge that the collection of the large volumes of clerical and clinical information required for this trial is made possible by the

\section{REFERENCES}

Anderson TJ, Sufi F, Ellis IO, Sloane JP, Moss S (2002) Implications of pathologist concordance for breast cancer assessments in mammography screening from age 40 years. Hum Pathol 33: 365-371

Day NE (1985) Estimating the sensitivity of a screening test. J Epidemiol Community Health 39: $364-366$

Forrest APM (1986) Breast Cancer Screening: Report to the Health Ministers of England, Wales, Scotland and Northern Ireland. London: HMSO

Hendrick RE, Smith RA, Rutledge JH, Smart CR (1997) Benefit of screening mammography in women aged 40-49; a new metaanalysis of randomized controlled trials. Monogr Natl Cancer Inst 22: $87-92$

Miller AB, To T, Baines CJ, Wall C (2002) The Canadian National Breast Screening Study-1: breast cancer mortality after 11-16 years of followup. Ann Intern Med 137: E-305-E-315

Moss S, for the Trial Steering Group (1999) A trial to study the effect on breast cancer mortality of annual mammographic screening in women starting at age 40. J Med Screening 6: $144-148$

Moss S, Waller M, Anderson TJ, Cuckle H, (writing committee) for the Trial Management Group (2005) Randomised controlled trial of mammo- enthusiasm and dedication of a multidisciplinary team of doctors, screening office managers, radiographers, nurses, clerical, secretarial and computing staff working at participating trial centers (as listed below), administrative staff at relevant Health Authorities and staff at pathology laboratories, cancer registries and regional quality assurance centres. Contributions from staff at the Trial Coordinating centre are gratefully acknowledged: Derek Coleman and Nicola Kingston for data processing and analysis, and Nicola Bixby and Yvonne Berg for case identification and pathology material collection.

Age Trial Centres: Avon Breast Screening, Aylesbury Breast Screening Service, Breast Test Wales, Cumbria Breast Screening Service, Epping Breast Screening Service, Greater Manchester Breast Screening Service, Hanley Breast Screening, Humberside Breast Screening Service, Newcastle Breast Screening Service, North of London Breast Screening Service, Nottingham Breast Screening, Pennine Breast Screening Programme, Peterborough Breast Imaging, Sheffield Breast Screening, South Derbyshire Breast Screening Service, South East London Breast Screening Service, South East Scotland Breast Screening Programme, Surrey Breast Screening Service, Warrington Breast Screening Service, Welcome Centre Breast Unit, West Sussex Breast Screening Service, Wiltshire Breast Screening Service and Wirral Breast Centre. graphic screening in women from age 40:predicted mortality based on surrogate outcome measures. Br J Cancer (submitted)

Moss SM, Coleman DA, Chamberlain J, Mapp TJ, for the United Kingdom Trial of Early Detection of Breast Cancer Group (1999) 16-year mortality from breast cancer in the UK Trial of Early Detection of Breast Cancer. Lancet 353: 1909-1914

Moss SM, Draper GJ, Hardcastle JD, Chamberlain J (1987) Calculation of sample size in trials for early diagnosis of disease. Int J Epidemiol 16: $104-110$

Nystrom L, Andersson I, Bjurstam N, Frisell J, Nordenskjold B (2002) Longterm effects of mammography screening: updated overview of the Swedish randomised trials. Lancet 359: 909-919

Shapiro S, Coleman EA, Broeders M, Codd M, de Koning H, Fracheboud J, Moss S, Paci E, Stachenko S, Ballard-Barbash R (1998) For the International Breast Cancer Screening Network (IBSN) and the European Network of Pilot Projects for Breast Cancer Screening. Breast cancer screening programmes in 22 countries: current policies, administration and guidelines. Int J Epidemiol 27: 735-742

Young KC (2002) Radiation doses in the UK trial of breast screening in women aged $40-48$ years. $\mathrm{Br} J$ Radiol 75: $362-370$ 